\title{
Multichannel analysis of neural oscillations in a simple model network - towards a better understanding of the spatiotemporal structure of brain oscillations Eckehard Olbrich ${ }^{* 1}$ and Thomas Wennekers ${ }^{2}$
}

\author{
Address: ${ }^{1}$ Max Planck Institute for Mathematics in the Sciences, D-04103, Leipzig, Germany and ${ }^{2}$ Centre for Theoretical and Computational \\ Neuroscience, University of Plymouth, PL4 8AA Plymouth, UK \\ Email: Eckehard Olbrich* - olbrich@mis.mpg.de \\ * Corresponding author
}

from Seventeenth Annual Computational Neuroscience Meeting: CNS*2008

Portland, OR, USA. 19-24 July 2008

Published: II July 2008

BMC Neuroscience 2008, 9(SuppI I):PI53 doi:I0.I I86//47I-2202-9-SI-PI53

This abstract is available from: http://www.biomedcentral.com/I47I-2202/9/SI/PI 53

(c) 2008 Olbrich and Wennekers; licensee BioMed Central Ltd.

Oscillatory patterns are an important feature prominent in EEG, MEG or local field potentials (LFP). Oscillations in a certain frequency range are often considered as entities related to some function of the brain, such as alpha waves in relaxed wakefulness, sleep spindles or slow oscillations in sleep, or beta and gamma oscillations in some cognitive processes. For single channel data several timefrequency analysis methods exist to analyze such oscillations. Applied to multi-channel data this approach leads to a picture of assigning each channel one oscillator, which becomes somewhat arbitrary if the same oscillation appears in several channels simultaneously. Source localization can cope with this problem, but still assumes the oscillators being localized entities. Here we assume in contrast that they are collective modes of the underlying neural networks, either extended or localized. In [1] we showed how slow parameter changes in a network can be traced based on a method to detect oscillatory patterns in single channel data using linear dynamical models. The present work extends this work to multiple channel measurements in order to identify collective oscillatory modes and to quantify their degree of locality.

The method was tested on artificial data with controllable properties: We simulated a two-dimensional noisy field of excitatory-inhibitory neural oscillators similar to the Wilson-Cowan equations but coupled over an adjustable lateral region. The system was augmented by an additional slow hysteresis loop, acting either globally or within Gaussian-weighted neighbourhoods, that could switch the local circuits between two operational states. Systematic parameter inhomogeneities (gradients, blocks, random values) could modulate the properties of local elements further. This allowed for a variety of homogeneous and inhomogeneous oscillatory and wave-like activation patters at single and multiple frequencies. An artificial "EEG" was then produced as local averages of neural activity.

Asking for generic properties of spatio-temporal phenomena visible in extended cortex-like structures, their causes, and their appearance in EEG-like measurements, we study different situations, e.g., (1) a homogeneous network with constant parameters, (2) the same network with a slow time dependence imposed on the coupling constants produced by a slow global closed-loop process, and (3) local slow processes introducing additional spatial inhomogeneities. All artificial multiple electrode EEG signals are analyzed by fitting linear models to short segments in a sliding window fashion. We compare the results of a local modeling, i.e. analyzing each channel separately, with a global model, where one model is fitted to all channels simultaneously. Implications of the simulation results and analysis method for real EEG are discussed in terms of distributed modes of cortical activation patterns and the signatures they cause in measurements. 


\section{References}

I. Olbrich E, Wennekers T: Dynamics of parameters of neurophysiological models from phenomenological EEG modelling. Neurocomputing 2007, 70:1848-1852.

Publish with Bio Med Central and every scientist can read your work free of charge

"BioMed Central will be the most significant development for disseminating the results of biomedical research in our lifetime. " Sir Paul Nurse, Cancer Research UK

Your research papers will be:

- available free of charge to the entire biomedical community

- peer reviewed and published immediately upon acceptance

- cited in PubMed and archived on PubMed Central

- yours - you keep the copyright

Submit your manuscript here:

http://www.biomedcentral.com/info/publishing_adv.asp 